\title{
ENAM Gene Mutation Factor in Amelogenesis Imperfecta
}

\author{
Apriani $\mathrm{A}^{1}$, Sembiring $\mathrm{LS}^{2}$, Suryatmojo $\mathrm{I}^{3}$, Sandra $\mathrm{F}^{4}$ \\ ${ }^{1}$ Post Graduate Student Faculty of Dentistry Trisakti University, Departement of Pediatric dentistry \\ Maranatha Christian University. \\ ${ }^{2}$ Post Graduate Student Faculty of Dentistry Trisakti University, Departement of Pediatric dentistry \\ Maranatha Christian University. \\ ${ }^{3}$ Post Graduate Student Faculty of Dentistry Trisakti University, Departement of Endodontic Maranatha \\ Christian University. \\ ${ }^{4}$ Department of Biochemistry and Molecular Biology, Faculty of Dentistry, Universitas Trisakti
}

\begin{abstract}
Amelogenesis Imperfecta (AI) is an abnormal disease that occurs in hard tissue of teeth. Clinical features of Amelogenesis Imperfecta look like immature enamel that looks like hypomaturation. The etiology of AI is influenced by the TGF- $\beta 1$ factor which is disturbed during the formation and development of enamel, one of which is caused by the presence of ENAM gene mutations. Further research on genetic history in the family and biomineralization of the formation of enamel important to be developed later.
\end{abstract}

Key words: Amelogenesis Imperfecta, ENAM gene, TGF- $\beta 1$

\section{Introduction}

Tooth enamel is the hardest tissue in the body, consisting of more than $98 \%$ minerals and less than $2 \%$ organic matrix and water, produced by deferred special cells known as ameloblast ${ }^{1}$ Enamel opacity is a qualitative enamel loss, involves changes in the translucency of the enamel and may appear white, yellow or brown in color. Enamel hypoplasia is a quantitative defect associated with reduced thickness of enamel. Amelogenesis imperfecta can be a form of enamel development defect. ${ }^{2,3,4}$

Enamel defects can also be caused by combination factors. There are more than 90 different factors that may be responsible for causing enamel development defects. Only a small percentage of these factors have been confirmed as factors that are directly responsible for causing developmental defects. ${ }^{5,6}$ The possible etiological factors for enamel developmental defects in permanent teeth can be broadly divided into two main categories: namely with local distribution (in the form of trauma, infection, irradiation) and with general distribution (genetic disorders, environmental factors, intoxication, malnutrition, perinatal problems or post natal, infection with a disease or a systemic condition). ${ }^{7}$

The formation of enamel can be separated into an initial stage involving secretion of matrix proteins such as amelogenin, ameloblastin and enamelin, and the subsequent stages of enamel mineralization and maturation, although this process can be present simultaneously during tooth development. ${ }^{8,9}$ Production and secretion of enamel proteins through relative gene expression on ameloblasts. The instruction signal which controls the transcription of amelogenin occurs before or during the initial stage. ${ }^{10}$ Amelogenesis Imperfecta can be inherited as a mutation in the gene that codes for the enamel protein. Mineralization is the key to the formation of enamel, and significant progress in understanding amelogenesis will be achieved by gaining a better understanding of the molecular events occurring in enamel mineralization. ${ }^{10}$ 
The autosomal dominant AmelogenesisImperfecta (ADAI) is the most common form of AmelogenesisImperfecta in the general population and has been associated primarily with mutations in the ENAM gene that encodes for enamelin protein. Enamelin is a specific acid protein that is expressed primarily by ameloblasts at the secretory stage. ${ }^{11}$ The secretory stage is the deposition of an organic matrix (preenamel formation) and partial mineralization of all enamel thicknesses. ${ }^{12}$ ENAM is located on $4 \mathrm{q}$ chromosome 13.3 and has 10 exons, 8 in some of which have been encoded. ${ }^{13}$ The first mutation identified in the ENAM gene causes an autosomal dominant AmelogenesisImperfecta with severe hypoplastic phenotype as a result of aberrant negative effect. ${ }^{14,15}$ Autosomal regression is also reported to cause ENAM gene mutations. ${ }^{16}$ The diagnosis of AmelogenesisImperfecta is very important. It can be based on symptoms, family history and clinical examination such as gene examination. Genetic tests for abnormal chromosomes although accurate; only as a research tool and clinical significance is still very poor because it is accurate inspection and gene mapping is needed. ${ }^{17}$

Determining the specific genotypes of Amelogenesis Imperfecta and phenotypes associated with pre-treatment Amelogenesis Imperfecta is important to optimize the prevention, treatment, and recovery of amelogenesis. ${ }^{12,18,19}$ By studying the results of various restorative procedures for each genotype / phenotype condition, dentists can use gene-based diagnosis to choose the most optimal treatment approach so that it can restore the state of the teeth in the best way. ${ }^{17,18}$ Predictive methods for determining genes that may be damaged, related to the patient's dental phenotype will be useful for alternative treatments. ${ }^{20}$

\section{TGF- $\beta 1$}

Role of Transforming Growth Factor TGF- $\beta 1$ is a signaling molecule that induces cell proliferation, cell differentiation, chemotaxis and apoptosis in monocytes and epithelial, mesenchymal and neuronal cells. ${ }^{21}$ TGF- $\beta 1$ signaling machines, including transmembrane receptor type serine kinases, occur in the central nervous system. There are 3 TGF- $\beta 1$ mammalian subtypes that have different distributions in the nervous system that show different nerve functions. TGF- $\beta 1$ has a multifunction whose nerve function is increasingly recognized. ${ }^{22}$

TGF- $\beta 1$ gene expression was observed during the process of enamel formation. TGF- $\beta 1$ is found in both mature enamel, and its activity tends to decrease when immature enamel transition to mature enamel. The in vitro studies have shown that latent TGF- $\beta 1$ is activated by matrix metalloproteinase (MMP20), and activated TGF$\beta 1$ is degraded by kallikrein-4 (KLK4). ${ }^{23}$ KLK4 mRNA levels are significantly reduced in teeth along with a slight increase in MMP-20 levels, indicating that maturation of normal enamel is regulated by TGF- $\beta 1$ which signifies through KLK4 expression. TGF$\beta$ signaling plays an important role in ameloblast function and maturation of enamel. ${ }^{24}$ Enamel protein is further degraded by KLK4, which is expressed by ameloblasts and the maturation stage. ${ }^{25}$

The complicated autocrine system of TGF- $\beta 1$ during enamel formation by showing gene expression, activation, inactivation, protein-protein interaction and TGF$\beta 1$ signaling induction during amelogenesis at both protein and genetic levels. ${ }^{23}$ In rodents, TGF- $\beta$ lis expressed developmental and mature ameloblasts and also detected in the inner dentition before enamel matrix secretion. ${ }^{26} \mathrm{TGF}-\beta 1$ is expressed during enamel organ differentiation and initiation of matrix secretion in human teeth. Hidden transcription of TGF- $\beta 1$ is expressed throughout the enamel formation. ${ }^{27}$ 


\section{TGF- $\beta 1$ influence ENAM gene}

The literature reports several genes associated with enamel formation features: amelogenin (AMELX), enamelin (ENAM), KLK-4, enamelysin or MMP-20, the ameloblastin gene, and recently identified DLX3, FAM83H, WDR72, and SLC4A4. ${ }^{28}$ The ENAM encodes the matrix proteins involved in the formation of enamel; it is located on chromosome 4, in position 71859495-71777517 from NM_031889 sequence. Enamelin is involved in enamel formation and is incorporated in crystals formed in enamel prisms and between them. Physical properties depend on enamel gene expression along with the amelogenin and ameloblastin genes. ${ }^{28}$ Mutations in the development regulating gene (TGF- $\beta 1$ ) are associated with dental development defects, at the morphodifferentiation stage is the stage of tooth formation that can cause an enamel defect. ${ }^{29}$

ENAM gene mutations in local hypoplastic Amelogenesis Imperfecta show that different mutations in the enamelin gene can lead to different clinical variants of local hypoplastic enamel and are smooth and thin from relatively small local defects to serious types of hypoplasia. ${ }^{12,30}$ The dominant mutation in ENAM genes also can cause an intermediate phenotype ("hypoplastic located") in which horizontal grooves and holes surround the enamel in the cervical third of a tooth with a high caries level. ${ }^{12,31,32}$

There are five different disease-causing mutations that have been identified in ENAM, which are explained by the standard nomenclature, the determination of mutations based on the predicted effects on the translation of enamel proteins: p. K53X; p.M71-Q157del and p.A158-Q178del; p.N197fsX277; and p.P422fsX448. ${ }^{32}$ The enamelin gene has been mapped on chromosome 4 as the ameloblastin gene (only $15 \mathrm{~kb}$ separates these genes), indicating that this region can contain a group of genes that encode enamel proteins. The first human enamel mutation was reported to be a single donor intron 7 base substitution site, substitution in exon 4, introducing premature codon stops. Recently, donor site mutations after enamelin codon 196 have been shown to cause autosomal dominant hypoplastic $\mathrm{AI}{ }^{33}$

\section{Mutation analysis ENAM}

ENAM or enamelin provides instructions for making a protein called enamelin, which is important for normal tooth development. At least seven mutations in the gene have been identified in humans with autosomal dominant ENAM genes from Amelogenesis Imperfecta. autosomal dominant derivative means that one copy of the ENAM gene in each cell changes. Some mutations reduce the amount of enamelin produced by genes, while other mutations cause production to become abnormal. ${ }^{34}$ Enamelin mutations cause hypoplastic forms of autosomal-dominant and recessive AI, with the phenotype ranging from relatively minor localized enamel pitting to severely hypoplastic enamel. ${ }^{35}$ ENAM is located on chromosome 4: base pair $71,494,460$ for abnormal and has been reported a novel enamelin gene mutation(g.4806A $>C$, IVS6-2A $>C$ ), and the third identification of the g.8344delGdefect, which provides further evidence of this being a mutational "hot spot"in the enamelin gene. ${ }^{34,35}$

The ENAM gene is sequenced as the most likely candidate gene in this AI family because of the general hypoplastic phenotype that has been previously associated with somedifferent ENAM mutations. The limit of exon and exon / intron from ENAM 
gene is amplified by PCR using foward and reverse primers. ${ }^{36,37}$ Beside using PCR the ENAM gene has been mapped within this locus by Radiation Hybrid Analysis (RHA) and Fluorescent In SituHybridization (FISH), and was therefore considered a candidate gene for this type of $\mathrm{AI} .^{38}$.

ENAM mutations that have been identified in this type of AI have about 7 types. ${ }^{39}$ Enamelin consists of the largest enamel protein and also the least of the three main forming proteins in the development of enamel. Enamel gene mutation in ENAM is a causative factor for $\mathrm{X}$-link, autosomal dominant and mutation in $\mathrm{N}$-terminal cause mutations $\mathrm{AI} .{ }^{31,32,39,40}$

\section{Advanced research on ENAM genes as a cause of Amelogenesis Imperfecta}

Further research on the ENAM gene is very important to be developed because of the strength of research and strategic gaps in the knowledge portfolio to synthesize this information towards recommendations for future progress. Enamel gene research can be ENAM genetic research and email biomeralalization studies. ${ }^{41}$

\section{Genetic research of ENAM}

In recent years, the correlation between $\mathrm{AI}$ and several genes that encode certain enamel proteins has been suggested for molecular research and mutation analysis. ENAM gen cause hypomaturation and hypoplasticAI with the autosomal pattern of inheritance. ${ }^{20}$ ENAM is an enamel protein, genetic testing for ENAM mutations can be examination of enamelin, the largest of EMP in the form of specific acid proteins expressed mainly by secretory stage ameloblasts. ${ }^{42}$

\section{Biomineralisation research}

Biomineralization research in dental development is now highly developed and provides a new molecular entry point that will enable researchers to describe new genetic pathways that regulate the biomineralization like FoxO1 and Smad3 act together to regulate the general repertoire of genes needed for maturation of complete enamel process which may also have significance for studies in human dental diseases such as amelogenesis imperfecta. ${ }^{43}$

The mechanism of mineralization is the key to enamel formation, and significant progress in our understanding of amelogenesis will be realized by gaining a better understanding of molecular events that occur early in enamel mineralization. ${ }^{44}$

\section{Conclusion}

Amelogenesis Imperfect is a disorder caused by gene mutations. Gene mutations that occur due to the regulation of TGF- $\beta 1$ are disrupted resulting in gene mutations, one of the mutations that occur regarding ENAM genes that affect chromosome 4. Examination of ENAM gene mutations can be done by genetic examination in individuals and in experimental animals. It is expected that in the future Amelogenesis Imperfecta can be predicted by gene examination and email biomineralization so that the incidence of Amelogenesis Imperfecta can be prevented and treatment becomes better.

\section{Reference}

1. Nanci A. Enamel: composition, formation, and structure. In: Nanci A, ed. Ten Cate's oral histology development, structure, and function. St Louis: Mosby, 2008:141-190. 
2. Masumo R, Bardsen A dan Nordrehaug A.Developmental defects of enamel in primary teeth and association with early life course events: a study of 6-36 month old children in Manyara, Tanzania. BMC Oral Health 2013, 13:21.

3. Shabtai Sapir dan Joseph Shapira.Clinical Solutions for Developmental Defects of Enamel and Dentin in Children. Pediatric dentistry. 2007. V 29/No 4 Jul/Aug.

4. Torres CRG dan Borges AB.Color Masking of Developmental Enamel Defects: A Case Series.Operative Dentistry, 2015, 40-1, 25-33..

5. Robinson C, Kirkham J, Shore R. Dental EnamelFormation to Destruction. 2017. CRC Press

6. Wong HM. Review Article Aetiological Factors for Developmental Defects of Enamel.Austin J Anat - Volume 1 Issue 1 - 2014.

7. Simmer JP, Richardson AS, Hu YY, Smith CE, Ching-Chun Hu J. A post-classical theory of enamel biomineralization and why we need one. Int J Oral Sci. 2012. Sep;4(3):129-34.

8. Jeremias F, Koruyucu M, Küchler EC, Bayram M, Tuna EB, Deeley K,et all. Genes expressed in dental enamel development are associated with molarincisor hypomineralization. Arch Oral Biol. 2013 Oct; 58 (10) :1434-42.

9. WK Seow. Developmental defects of enamel and dentine: challenges for basic science research and clinical management. Australian Dental Journal 2014; 59:(1 Suppl): 143-154.

10. Margolis HC, Kwak S-Y, Yamazaki H. Role of mineralization inhibitors in the regulation of hard tissue biomineralization: relevance to initial enamel formation and maturation. Front Physiol. 2014; 5: 339

11. Hu, P., Lacruz, R. S., Smith, C. E., Smith, S. M., Kurtz, I., and Paine, M. L. (2012). Expression of the sodium/calcium/potassium exchanger, NCKX4, in ameloblasts. Cells Tissues Organs 196, 501-509

12. Georgios Chatzopoulos, Dimitrios Tziafas Balk. Molecular Basis of Human Enamel Defects J Dent Med, Vol 18, 2014

13. S Gutiérrez, D Torres, I Briceño, Ana Maria Gómez dan Eliana Baquero. Clinical and molecular analysis of the enamelin gene ENAM in Colombian families with autosomal dominant amelogenesis imperfect. Genetics and Molecular Biology, 35, 3, 557-566 (2012)

14. Rajpar, M. H., Harley, K., Laing, C., Davies, R. M., and Dixon, M. J. Mutation of the gene encoding the enamel-specific protein, enamelin, causes autosomaldominant amelogenesis. (2001).

15. Claire E. L. Smith1, 2*, James A. Poulter2, Agne Antanaviciute3, Jennifer Kirkham1, Steven J. Brookes1, Chris F. Inglehearn2 and Alan J. Mighell2 Amelogenesis Imperfecta; Genes, Proteins, and Pathways. 2017

16. Chen, C. L., Bromley, K. M., Moradian-Oldak, J., and DeYoreo, J. J. (2011). In situ AFM study of amelogenin assembly and disassembly dynamics on charged surfaces provides insights on matrix protein self-assembly. J. Am. Chem. Soc. 133, 17406-17413

17. C Jayam, S Soni, D Roy. Amelogenesis Imperfecta- ReviewAnd Case Report. Rujods, Ranchi University, Vol - 2 No.-1 June 2013

18. G. Stephanopoulos, M.-E. Garefalaki, and K. Lyroudia, "Genes and related proteins involved in amelogenesis imperfecta," Journal of Dental Research, vol. 84, no. 12, pp. 1117-1126, 2005. 
19. R. G. Lindemeyer, C. W. Gibson, and T. J. Wright, "Amelogenesis imperfecta due to a mutation of the enamelin gene: clinical case with genotype-phenotype correlations," Pediatric Dentistry, vol. 32, no. 1, pp. 56-60, 2010.

20. Fernanda Veronese Oliveira, Carla Vecchione Gurgel, Tatiana Yuriko Kobayashi, Thiago José Dionísio,2 Lucimara Teixeira Neves,2,3 Carlos Ferreira Santos,2 Maria Aparecida Andrade Moreira Machado, and Thais Marchini Oliveira1. Amelogenesis Imperfecta and Screening of Mutation in Amelogenin Gene.Hindawi Publishing CorporationCase Reports in DentistryVolume 2014, Article ID 319680, 5 pages. Volume 2014,

21. Kubiczkova, L., Sedlarikova, L., Hajek, R. \& Sevcikova, S. TGF- $\beta 1$ - an excellent servant but a bad master. J Transl Med10, 183 (2012)

22. Dobolyi A, Vincze $C$, Pál G, Lovas $G$; The Neuroprotective Functions of Transforming Growth Factor Beta Proteins. J. Mol. Sci.2012

23. Kobayashi S, Yamakoshi Y, Asada Y, TGF- $\beta 1$ autocrine signaling at secretorystage enamel, Journal of oral Biosciences, 2016.

24. Cho A, Haruyama N, Hall B, Mary Jo S. Danton, Zhang L, Arany P, Mooney P,Harichane Y, Goldberg M, Gibson C, Kulkarni A, GF-B Regulates Enamel Mineralization and Maturation through KLK4 Expression, 2013

25. Simmer, J. P. et al. Why Does Enamel in Klk4 Null Mice Break Above the Dentino-Enamel Junction? Cells Tissues Organs 194, 211-215 (2011)

26. Gao, Y. et al. TGF- $\beta 11$ and TGFBR1 are expressed in ameloblasts and promote MMP20 expression. Anatomical record (Hoboken, NJ, 2007) 292, 885-890 (2009).

27. Yamakoshi, Y. et al. MMP20 and KLK4 activation and inactivation interactions in vitro. Arch Oral Biol 58, 1569-1577 (2013).

28. I. G. Udina and O. V. Gulenko. Molecular-Genetic Mechanisms of Caries Development. Russian Journal of Genetics. Vol. 54, No. 4, pp.415-422. (C) Pleiades Publishing, Inc., 2018.

29. AH. Brook. Multilevel complex interactions between genetic, epigeneticand environmental factors in the aetiology of anomalies ofdental development. archives of oral biology 54s (2009) s3-s17

30. Carina et all.A nonsense mutation in the enamelin genecauses local hypoplastic autosomal dominantamelogenesis imperfecta (AIH2).Human Molecular Genetics, 2002, Vol. 11, No. 9

31. Sandra Gutiérrez, Diana Torres2, Ignacio Briceño, Ana Maria Gómez and Eliana Baquero. Clinical and molecular analysis of the enamelin geneENAMin Colombianfamilies with autosomal dominant amelogenesis imperfecta. Genetic and Moleculler Biology. Volume 35, 3, 557-566 (2012)

32. Jung-Wook Kim, James P.Simmer, Brent P.-L. Lin, FigenSeymen, John D. Bartlett, Jan C.-C.Hu. Mutational analysis of candidate genes in 24 amelogenesis imperfect families. Eur J Oral Sci 2006; 114 (Suppl. 1): 3-12

33. Maria Cristina Leme Godoy Dos Santos, Sergio Roberto Peres Line. The Genetics Of Amelogenesis ImperfectaA Review Of The Literature. J Appl Oral Sci2005; 13(3): 212-7.

34. Harun A, Hasanuddin $\mathrm{T}$ and, Mardiana Adam. Amelogenesis Imperfecta in Children: Review of Pathogenetic Aspect. IJSR. 2017 . Volume 6 Issue 4.

35. J.W. Kim, F. Seymen, B.P.J. Lin, B. Kiziltan, K. Gencay, J.P. Simmerand J.C.-C. Hu. ENAM Mutations in Autosomal-dominant AmelogenesisImperfecta. J Dent Res. 2005. 84(3): 278-282 
36. Rochelle G. Lindemeyer,Carolyn W. Gibson and Timothy J. Wright. Amelogenesis Imperfecta Due to a Mutation of the Enamelin Gene:Clinical Case With Genotypephenotype Correlations. Pediatr Dent. 2010 ; 32(1): 56-60

37. T C Hart, P S Hart, M C Gorry, M D Michalec, O H Ryu, C Uygur, D Ozdemir, S Firatli, G Aren,E Firatli. NovelENAMmutation responsible for autosomal recessiveamelogenesis imperfecta and localised enamel defects. $\mathrm{J}$ Med Genet2003;40:900-906

38. Mayur Chaudhary, Shweta Dixit and Sanket Kunte. Amelogenesisimperfecta: Report of a case and review of literature. J Oral MaxillofacPathol. 2009. Jul-Dec ; 13(2) :70-77.

39. Jan C.-C. Hu, Yong-Hee P. Chun, Turki Al Hazzazzi and James P. Simmer. Enamel Formation and AmelogenesisImperfecta. Cells Tissues Organs 2007; 186:78-85.

40. Steven J. Brookes, Martin J. Barron, Claire E.L. Smith, James A. Poulter, Alan J. Mighell, Chris F. Inglehearnet all. Amelogenesis imperfecta caused by Nterminalenamelin point mutations in mice and men is drivenby endoplasmic reticulum stress. Human Molecular Genetics, 2017, Vol. 26, No. 10 1863-1876

41. Jennifer Kirkham, Steven J. Brookes, Thomas G. H. Diekwisch, Henry C. Margolis, Ariane Berdal, and Michael J. Hubbard. Enamel Research: Priorities andFuture Directions. Frontiers in Physiology | www.frontiersin.org 1 July 2017 | Volume 8 | Article 513.

42. Claire E. L. Smith, James A. Poulter, Agne Antanaviciute, Jennifer Kirkham, Steven J. Brookes, Chris F. Inglehearn, and Alan, J. Mighell. Amelogenesis Imperfecta; Genes,Proteins, and Pathways. Frontiers in Physiology | www.frontiersin.org 1 June 2017| Volume 8 | Article 435

43. PocheRA, Sharma R, Garcia MD, Wada AM, Nolte MJ, et al. Transcription Factor FoxO1 Is Essential for Enamel Biomineralization. PLoS ONE. 2012: 7(1):e30357. doi:10.1371/journal.pone.0030357.

44. James P Simmer, Amelia S Richardson, Yuan-Yuan Hu, Charles E Smithand Jan Ching-Chun Hu. A post-classical theory of enamel biomineralization... andwhy we need one. International Journal of Oral Science .2012: 4, 129-134; doi:10.1038/ijos.2012.59. 